\title{
MEDIA STUDENTS' CAPABILITY TO INTERACT WITH AUgMENTED REALITY AND 3D ANIMATIONS IN VIRTUAL BROADCAST NEWS STUDIOS
}

\author{
Tariq Alrimawi ${ }^{1}$ and Wasan Haddad ${ }^{2}$ \\ ${ }^{1}$ Department of Animation \& Multimedia, University of Petra, Amman, Jordan \\ ${ }^{2}$ Department of Radio \& Television, University of Petra, Amman, Jordan
}

\begin{abstract}
The latest technological developments continually affect all fields, including through the implementation of augmented reality $(A R)$ in media broadcasting. The use of $A R$ can improve the public image of broadcasting and allow international, national, and regional information and stories to be presented impressively and effectively. Furthermore, AR will allow presenters to interact with television stories through a three-dimensional (3D) virtual environment as well as provide the viewer with rich information about the world. However, undergraduate media departments at most universities in Jordan are still teaching news presentation in basic newsrooms. Therefore, this paper presents an experimental collaboration between the Television Department and Animation \& Multimedia Department at the University of Petra; an AR virtual studio and $3 D$ computer graphics animation were used to teach performance skills to students who aim to become television news anchors after graduation. This experimental research provides students with a new approach and tool for storytelling, including techniques to deal with technological evolution in the media field. This paper evaluates the impact of employing virtual worlds in newscasts as an effective method of education delivery for Jordanian students, and also offers suggestions for improving the curricula of radio and television departments. Such improvements will enable media students who are interested in working as presenters or news broadcasters to gain skills and experience in interacting with $3 D$ animated elements. The results of this research revealed that media students and graduates would be more successful in the media industry if they mastered the skills of communication, presentation, and acting performance to interact with virtual environments and virtual $3 D$ animated objects. These skills could lead to improved employment opportunities after graduation. Accordingly, this study aimed to present solutions and motivate universities in Jordan to apply the AR virtual studio as a powerful tool for presenting stories.
\end{abstract}

\section{KEYWORDS}

Augmented Reality, Virtual Studio, Three-Dimensions, Animation, News Broadcasting, Instructional Multimedia, Undergraduate Students, Higher Education

\section{INTRODUCTION}

Rapid technological change has had a positive impact on the broadcasting industry. Some of the latest technologies in the media industry include the use of augmented reality (AR) and virtual studios (VSs), which help television channels to tell stories to viewers visually in order for them to understand and experience events in a way that closely resembles reality. Consequently, viewers are encouraged to watch the channel continually, which is advantageous given the high level of competition among Arab news channels.

It is clear that the implementation of AR in the Middle East is still limited. Therefore, scholars in the region need to fill the gap and contribute more knowledge about this new technology, which will be a crucial and powerful tool for developing media there. To attract the audience using a 
modern rather than traditional style, it is imperative for news channels to maintain pace with this technology in their technical preparation and production of news material. Consequently, these developments in the media field place new responsibilities on Jordanian and Arab universities to provide programmes, courses, facilities such as VSs (e.g., Chroma Studios), television broadcasting equipment, and lighting to ensure graduates have developed the necessary skills to keep abreast of the changing world of media and communication. Surprisingly, most of the Radio and Television Departments at the universities in Jordan, and Arab countries, are still teaching students the traditional way of presenting stories and reading the news. Students are taught to use a simple newsroom that contains a studio news desk, chair, a static printed poster behind the desk, and a teleprompter from which to read.

In fact, modern technology has enhanced the implementation of multimedia technology, and traditional education is slowly shifting from listening and observation only to including more activity courses, which provide students with the principles for discovery. An opportunity exists to change traditional teaching practices in higher education to have interactive content through the effective use of digital tools; students can be provided with a high-quality learning environment using tools such as animation, sound, kinetic typography, and motion graphics [1].

This paper presents suggestions for improving the curricula of radio and television departments such that media students who are interested in working as presenters or news broadcasters can gain skills and experience in interacting with virtual three-dimensional (3D) animated elements and not only using words with static pictures. These skills could lead them to improved employment opportunities after graduation.

Amarin asserted that two-dimensional (2D) and 3Danimations can be designed to help students conquer information overload through directing visually important information. In addition, multimedia technology emphasises active learning initiatives and is crucial for improving learner's 'intellectual, emotional and social experience, as well as it may support the use of diverse teaching strategies and learning methodologies, and can promote diverse thinking skills among learners.' [2]

\subsection{Research Questions}

New challenges face the specialised fields of radio and television in terms of how lecturers and students can remain upto date with technology related to AR, multimedia, and 3D animation in news broadcasting, sports, weather, and other frameworks and media arts. Therefore, this research sought to address the following questions:

- How do media facilities at universities in Jordan keep abreast of new technologies related to the media industry's use of AR in VSs?

- Do media students have to advance their skills in communication, presentation, and performance to interact with virtual 3D animated elements around them?

To answer the research questions, several interviews were conducted with lecturers from the University of Petra; these interviews focused on reviewing the curricula and courses of the Radio and Television Department. Subsequently, three participants were selected for an experiment to test their performance and interaction with $3 \mathrm{D}$ AR in virtual broadcast news studios. The participants were University of Petra students from the Television and Radio Department, and they did not have any experience in presenting with AR prior to this experimental research. 


\subsection{Methodology and Methods}

Qualitative and experimental research methods were applied to observe participants (students) in action; therefore, this research was conducted through experiments on sample groups of television news presenters (media students) to compare news headlines announced in a newsroom (i.e., 'telling the story') with the use of VSs and AR (i.e., 'living the story'). This approach offered the presenter a 3D experience in which both the presenter and the environment engaged in constant movement and interaction. The presenter could visualise, 'feel, act and react as they would in a corresponding real-world' scene [3].

The main objective of this research was to examine the 'show, don't tell' technique using AR and VSs to provide academics and students with a powerful tool for digital media production. This tool can improve the quality of educational theory, practice, and learning outcomes in mass communication and media programmes at universities in Jordan by highlighting the uniqueness that interaction with the virtual world and the latest technology offers. In addition, this project aims to keep industry in Jordan upto date with the latest developments in AR and VSs. Moreover, this project aims to provide television presenters (students) with the methods to use real time and studio space while appearing to be within the $3 \mathrm{D}$ virtual world, and also to test the level of interaction with this world. Finally, this project will improve the digital media and multimedia facilities at the University of Petra and provide the latest technology for students.

\subsection{Academic Point of View}

Most universities in Jordan, including universities in the Arab region, still use the traditional method of teaching television presentation skills using a traditional newsroom (Figure 1); this approach produces graduates who are unable to deal with AR techniques used by local and Arab television channels. Most academics who were interviewed emphasised that technology and television news broadcasting cannot be separated; technological development greatly affects media products, especially news broadcasting, and has a strong impact on the audience. In addition, the use of AR materials in the production of news is a necessity to help channels deliver understandable information to the audience. Modern digital technologies have provided television news production with effective solutions for shaping screen language.

Dr Tayseer Masharqa, a lecturer at the Department of Radio and Television at the Faculty of Mass Communication, University of Petra, claimed that modern and effective media organisations need contemporary techniques for television news broadcasting. These techniques include utilising VSs and training students in performance and presentation skills to enable them to work with the latest electronic equipment and devices related to VSs. Dr Masharqa added that media students' passion for presenting in front of the camera will increase with the use of these high-quality technologies within Jordanian universities. Moreover, he explained that 'Performing is an audiovisual art, and their misapplication in the VS makes digital formulation poor, or contradictory. That spoils everything'.

Similarly, Dr Abdul Karim Al-Dubaisi, another lecturer at the same Department of Radio and Television, stated that the use of multimedia in the production of news has become a necessitynot only to enhance the aesthetics of the material presented but also to bring the picture to the viewer in a simplified way. He suggested that universities should train students on how to deal with new technologies, especially with VSs, to match the performance of the student with oral message delivery. Such training would require the Faculty of Mass Communication to modify and add courses as well as improve educators' abilities to deal with these developments for achieving advanced learning outcomes. 
International Journal of Computer Graphics \& Animation (IJCGA) Vol.10, No.2/3, July 2020

Furthermore, Dr Nisreen Abdallah, a lecturer at the Department of Media and Journalism at the Faculty of Mass Communication, University of Petra, reported that 'seeing is believing' and that the effect of AR on news broadcasting and delivery is strong because it contains visible details such as formal elements, motion, and a sense of the third dimension in its true proportions. She pointed out that virtual scenes differ from reality, but they can communicate information in the best possible way. She emphasised that using the VS makes it easier for the viewer to understand the story, but it is difficult for the presenter to communicate the story through the use of AR tools and a virtual environment; they need imagination, special skills such as concentration, as well as acting skills.

Today, the challenge facing the production of television news programmes is the need to preserve the content and truthfulness of news while making it visually attractive. The content should be understood by as many viewers as possible, because the public seeks news that provides clear, uncomplicated information. However, there is no doubt that entertainment programmes attract more viewers compared with the news, and television news broadcasting is based on journalism and not entertainment programmes[4].

\subsection{Definitions}

Early AR technologies were publicised by important work from scholars Paul Milgram, Fumio Kishino, and Roland T. Azuma in the 1990s. However, within the last few years, AR has developed from research laboratories and academic papers into the implementation of AR technology to bring users closer to reality in many areas, such as videogames, healthcare, engineering, tourism, publishing, architecture and interior design, visual arts, mass media, the military, and education. It has also been identified as one of the technologies changing the face of higher education [5].

$\mathrm{AR}$ is defined as the integration of still or animated images as virtual objects with a real environment [6]. Another definition is that AR either transfers real physical elements into the virtual environment or conjures virtual elements within the real environment [7]. Ronald Azuma argued that $\mathrm{AR}$ can persuasively include virtual $3 \mathrm{D}$ objects and place them in the context of reality, but those objects are not actually related to reality [8]. However, in this research, we used $\mathrm{AR}$ and a VS, which entailed incorporating 3D animated virtual objects within the VS; these objects are invisible to the presenter but physically visible to the viewer.

\section{Review of Related Work}

The main purpose of this study was to investigate the presentation skills of media students when using the VS and interact with virtual objects to tell a story in the newsroom and compare this with the traditional way. Therefore, the focus of this research concerned the implementation of $\mathrm{AR}$ and 3D animations in virtual broadcasting, about which little has been specifically written.

We briefly reviewed papers that varied between examining the space and virtual elements as well as the interaction using AR. From a different perspective, one study highlighted the challenges that might be faced when using AR and their elements to mix reality with virtual reality in acting [9]. Other studies have observed the implantation and impact of A Rexperiences for visitors in museums, whereas another study examined the interaction of a virtual set and dealing with space and virtual elements [10].

Interestingly, much research has focused on multimedia learning and its effectiveness at improving students' performance [11]-[12]-[13].Research on multimedia principles has shown that animation is a more effective learning tool compared with static graphics, and 'more and more educational materials seem to prefer graphics to be animated wherever possible' because it 
International Journal of Computer Graphics \& Animation (IJCGA) Vol.10, No.2/3, July 2020

helps learners develop their own set of mental models but the learners 'must extract thematically relevant information from the animation and incorporate it into their knowledge structures.' [14]It was not our intention to study the mental models in education, which we believe would be an important topicto cover in a future study. Another important topic to cover in the future is how to develop the mental models of media students when they move from telling the story in the newsroom to living the story with virtual objects in the virtual studio.

\section{EXPERIMENTAL RESEARCH DESIGN}

As mentioned previously, the selected students had learned the traditional method of presenting news through the use of a traditional broadcasting studio (Figure 1). This approach is a useful method of teaching students the basics of news presentation, including the contribution of their appearance, techniques that help reduce feelings of nervousness, the use of clear and simple language, voice quality, proper breathing, the development of a clear and interesting delivery style, and many other presentation and voice skills [15]. However, the university could enhance their education using AR for television news broadcasting presentations. In this manner, students would be provided with a foundation of knowledge and skills to use technology, including the ability to integrate new technologies in the field of mass media.

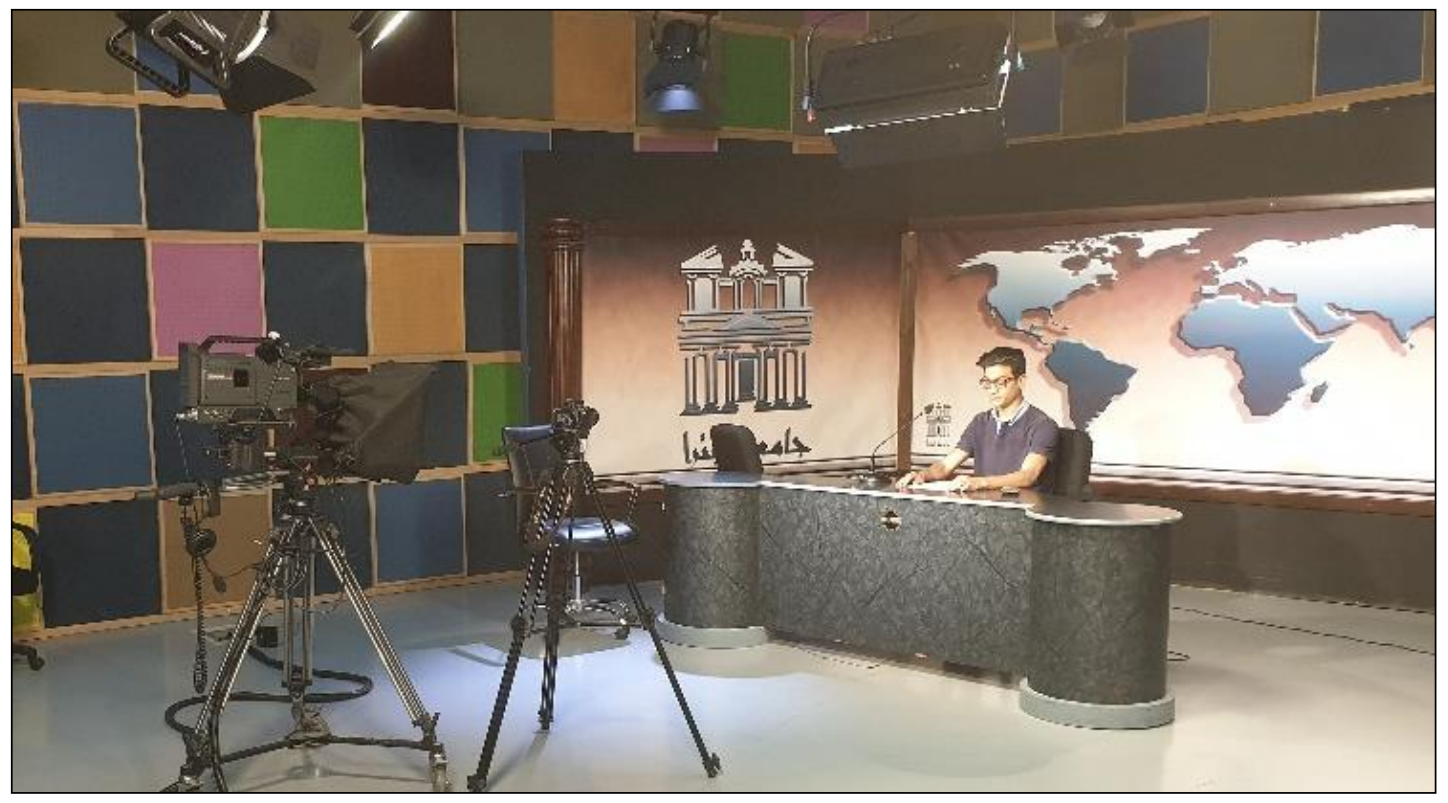

Figure 1. The newsroom at the University of Petra

Dr Najwa Khandaqji, a lecturer specialising in performing arts and drama at the Lebanese International University, reported that the use of AR in VSs has the ability to evoke far-off places and transfer the appropriate visual image to closely match reality. She attributed the capturing of viewers' attention to the visual fascination provided by this technology. In addition, AR technology facilitates the transfer of information but simultaneously reduces the volume of information transferred. Consequently, to reach a stage where a VS becomes a necessity in the media faculties of universities, universities must provide the necessary technical requirements. Dr Khandaqji elaborated this as follows: 'You cannot reach an understanding of skills without understanding the goals and, therefore, the tools they achieve'. Dr Khandaqji stated that a lack of performance skills among students at media faculties will lead to a loss of these techniques and their role and impact. Furthermore, the absence of these skills will make news broadcasts less engaging, which will have a detrimental effect on the entire news process. 
International Journal of Computer Graphics \& Animation (IJCGA) Vol.10, No.2/3, July 2020

Visual communication studies have shown that using images and words together creates a rich combination that has a better effect on the viewer and learners than words alone. Images attract television viewers more effectively than oral messages only and are retained in their memory for longer. This is not a new approach, but a return to ancient times when images were used to document and record daily life [16]. It is undeniable that the use of images, whether in 2D or 3D visual designs, is increasing in most activities and daily communication through mobile applications, social networking sites, and various digital platforms.

News broadcasting in the Middle East is rigid in format and contains mostly negative news. The media industry has attempted to alleviate the sombreness of the news by having a co-presenter or animated virtual objects that function as a virtual partner within the news studio. The presenters of influential programmes should possess the skills to deal with this virtual partner as well as knowledge of the power of this tool. New developments in technology will continue, and viewer preferences force the media industry to maintain pace with these developments. Consequently, presenters must have the capability to deal with technological advances.

The production of television material involves several stages that require time, effort, and considerable financial investment. Those who appear in front of the screen can cause this material to fail or succeed. Dr Alhakim Masoud, a lecturer at the School of Audio Engineering in Jordan (SAE Institute) who specialises in modern media skills, dramatic space, directing, and acting, suggested that presenters should know the target audience and what impression they will make on the viewer. Emotions and body language provide much information to the viewer, and presenters must be honest in their performance and not underestimate the intelligence of the audience. As Dr Masoud explained, 'The best journalist is the one who does not differ much in front of the camera from his true personality'.

It is crucial that the presenter makes the viewer feel the reality of the existence of virtual elements through dealing with the five senses. Viewers should perceive presenters as seeing, hearing, smelling, tasting, and touching these elements as they interact with them and should be convincingly influenced without exaggeration. The presenter must be aware of the difference between being an actor and a successful presenter. Acting is a type of performance that involves portraying different characters, whereas successful presenters should have the skills to deliver different stories. Successful presenters must be comfortable with animated virtual objects inside the VS and convince the viewer that they are moving naturally around real objects in a real environment. These are skills that take time and patience to develop [17].

This research aimed to improve students' skills in visualisation, presentation, and performance within a 3D AR. Therefore, it was necessary to prepare the University of Petra's infrastructure for a new VS, including a green screen, camera, lighting unit, sound system, and control room (Diagram 1; Figure 2). This research emphasises the importance of giving students new tools in education, as expressed by Richard Buckminster Fuller: 'If you want to teach people a new way of thinking, don't bother trying to teach them. Instead, give them a tool, the use of which will lead to new ways of thinking'.

Dr Najwa Khandaqji, a lecturer specialising in performing arts and drama at the Lebanese International University, reported that the use of AR in VSs has the ability to evoke far-off places and transfer the appropriate visual image to closely match reality. She attributed the capturing of viewers' attention to the visual fascination provided by this technology. In addition, AR technology facilitates the transfer of information but simultaneously reduces the volume of information transferred. Consequently, to reach a stage where a VS becomes a necessity in the media faculties of universities, universities must provide the necessary technical requirements. Dr Khandaqji elaborated this as follows: 'You cannot reach an understanding of skills without 
International Journal of Computer Graphics \& Animation (IJCGA) Vol.10, No.2/3, July 2020

understanding the goals and, therefore, the tools they achieve'. Dr Khandaqji stated that a lack of performance skills among students at media faculties will lead to a loss of these techniques and their role and impact. Furthermore, the absence of these skills will make news broadcasts less engaging, which will have a detrimental effect on the entire news process.

Visual communication studies have shown that using images and words together creates a rich combination that has a better effect on the viewer and learners than words alone. Images attract television viewers more effectively than oral messages only and are retained in their memory for longer. This is not a new approach, but a return to ancient times when images were used to document and record daily life [16]. It is undeniable that the use of images, whether in 2D or 3D visual designs, is increasing in most activities and daily communication through mobile applications, social networking sites, and various digital platforms.

News broadcasting in the Middle East is rigid in format and contains mostly negative news. The media industry has attempted to alleviate the sombreness of the news by having a co-presenter or animated virtual objects that function as a virtual partner within the news studio. The presenters of influential programmes should possess the skills to deal with this virtual partner as well as knowledge of the power of this tool. New developments in technology will continue, and viewer preferences force the media industry to maintain pace with these developments. Consequently, presenters must have the capability to deal with technological advances.

The production of television material involves several stages that require time, effort, and considerable financial investment. Those who appear in front of the screen can cause this material to fail or succeed. Dr Alhakim Masoud, a lecturer at the School of Audio Engineering in Jordan (SAE Institute) who specialises in modern media skills, dramatic space, directing, and acting, suggested that presenters should know the target audience and what impression they will make on the viewer. Emotions and body language provide much information to the viewer, and presenters must be honest in their performance and not underestimate the intelligence of the audience. As Dr Masoud explained, 'The best journalist is the one who does not differ much in front of the camera from his true personality'.

It is crucial that the presenter makes the viewer feel the reality of the existence of virtual elements through dealing with the five senses. Viewers should perceive presenters as seeing, hearing, smelling, tasting, and touching these elements as they interact with them and should be convincingly influenced without exaggeration. The presenter must be aware of the difference between being an actor and a successful presenter. Acting is a type of performance that involves portraying different characters, whereas successful presenters should have the skills to deliver different stories. Successful presenters must be comfortable with animated virtual objects inside the VS and convince the viewer that they are moving naturally around real objects in a real environment. These are skills that take time and patience to develop [17].

This research aimed to improve students' skills in visualisation, presentation, and performance within a 3D AR. Therefore, it was necessary to prepare the University of Petra's infrastructure for a new VS, including a green screen, camera, lighting unit, sound system, and control room (Diagram 1; Figure 2). This research emphasises the importance of giving students new tools in education, as expressed by Richard Buckminster Fuller: 'If you want to teach people a new way of thinking, don't bother trying to teach them. Instead, give them a tool, the use of which will lead to new ways of thinking'. 
International Journal of Computer Graphics \& Animation (IJCGA) Vol.10, No.2/3, July 2020

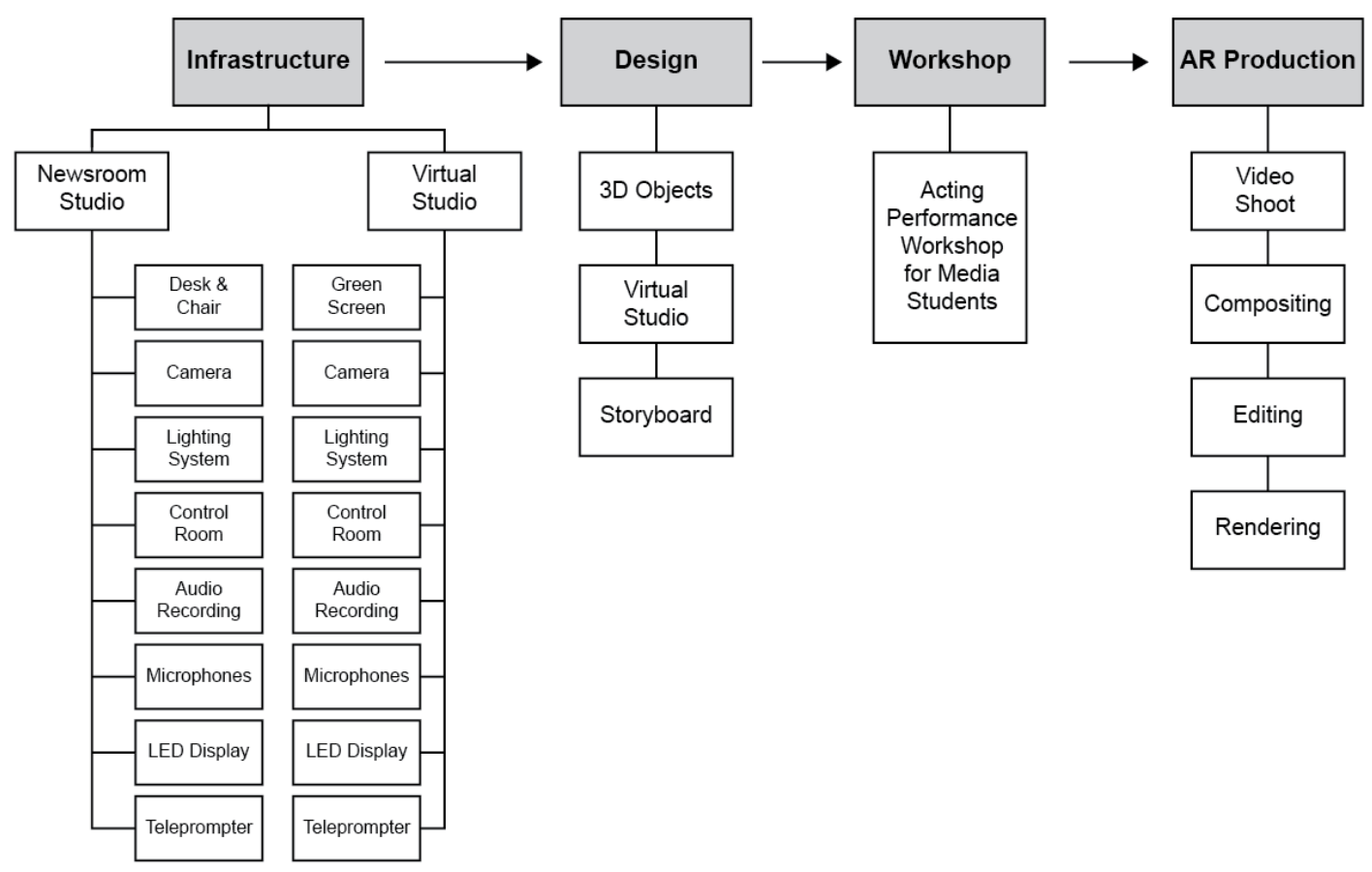

Diagram 1. Schematic structure of the experimental research at the University of Petra

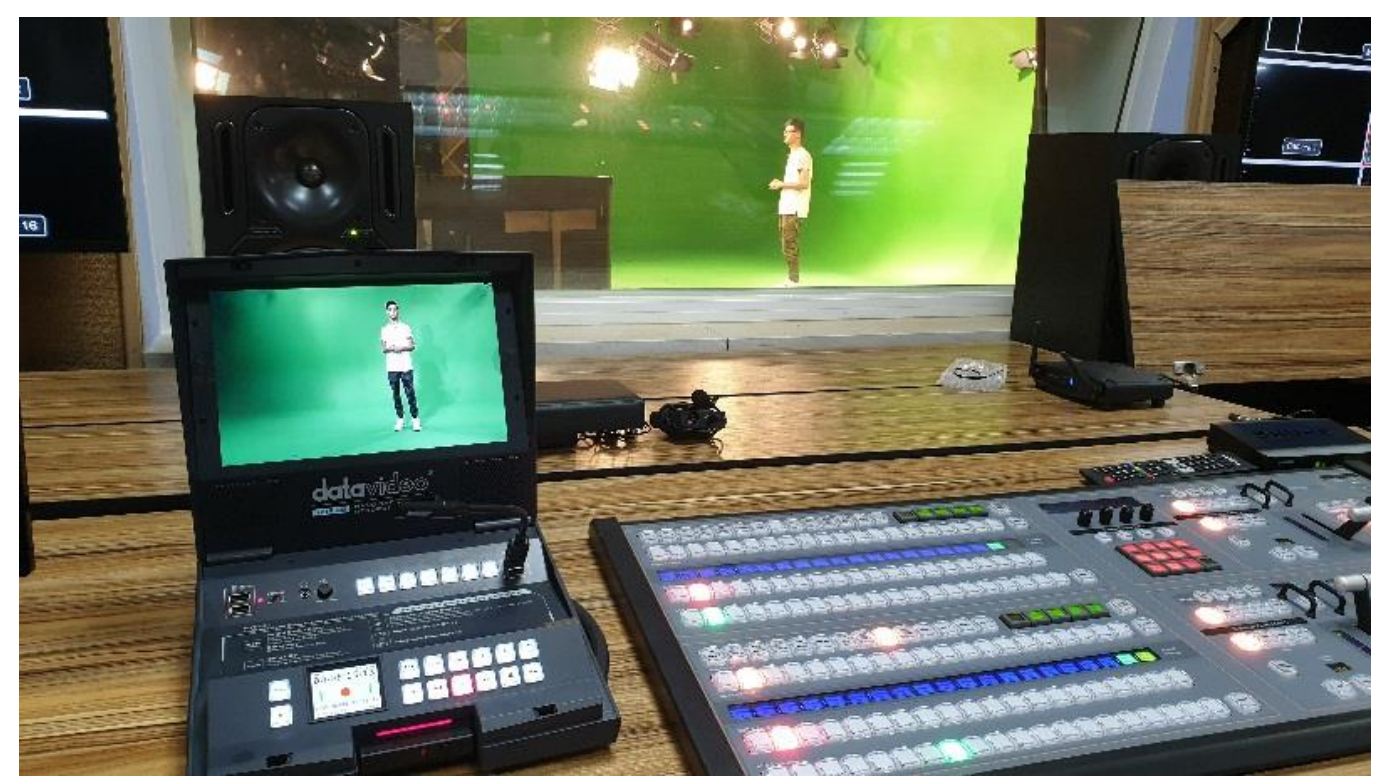

Figure 2. New virtual studio at the University of Petra

\section{DESIGN AND DEVELOPMENT}

The development of the VS involved specific object modelling, VS design, and storyboarding processes that were incorporated into the virtual scene. The students and teacher assistants in the animation/multimedia department designed a3D computer graphic of three tanks displayed at the Royal Tank Museum in Amman, the capital city of Jordan. We started modelling each piece of the tanks separately until we reached the final shape. The next step was mapping each piece to prepare it for the texturing step. Then, we rigged the tanks to make them movable with controls to enable the animator to move a tank and key frame it. Thereafter, we added lights and shadows 
International Journal of Computer Graphics \& Animation (IJCGA) Vol.10, No.2/3, July 2020

(Figure 3) and finally completed the rendering stage. After finishing the 3D modelling stage, we created simple and spacious studios with blank spaces to emphasise the news anchor and to be adjusted later with 3D virtual models and graphics (Figure 4).

We worked on incorporating the virtual elements beside the presenter such that they appeared realistic; for example, by adding shadows and reflections of objects. This process is essential for the interaction between the presenter, virtual objects, and virtual newsroom to attract viewers' interest in watching the news. In addition, animation and multimedia students were able to use their skills to help build the graphic library of 3D objects and architectural components to be added to the virtual world.

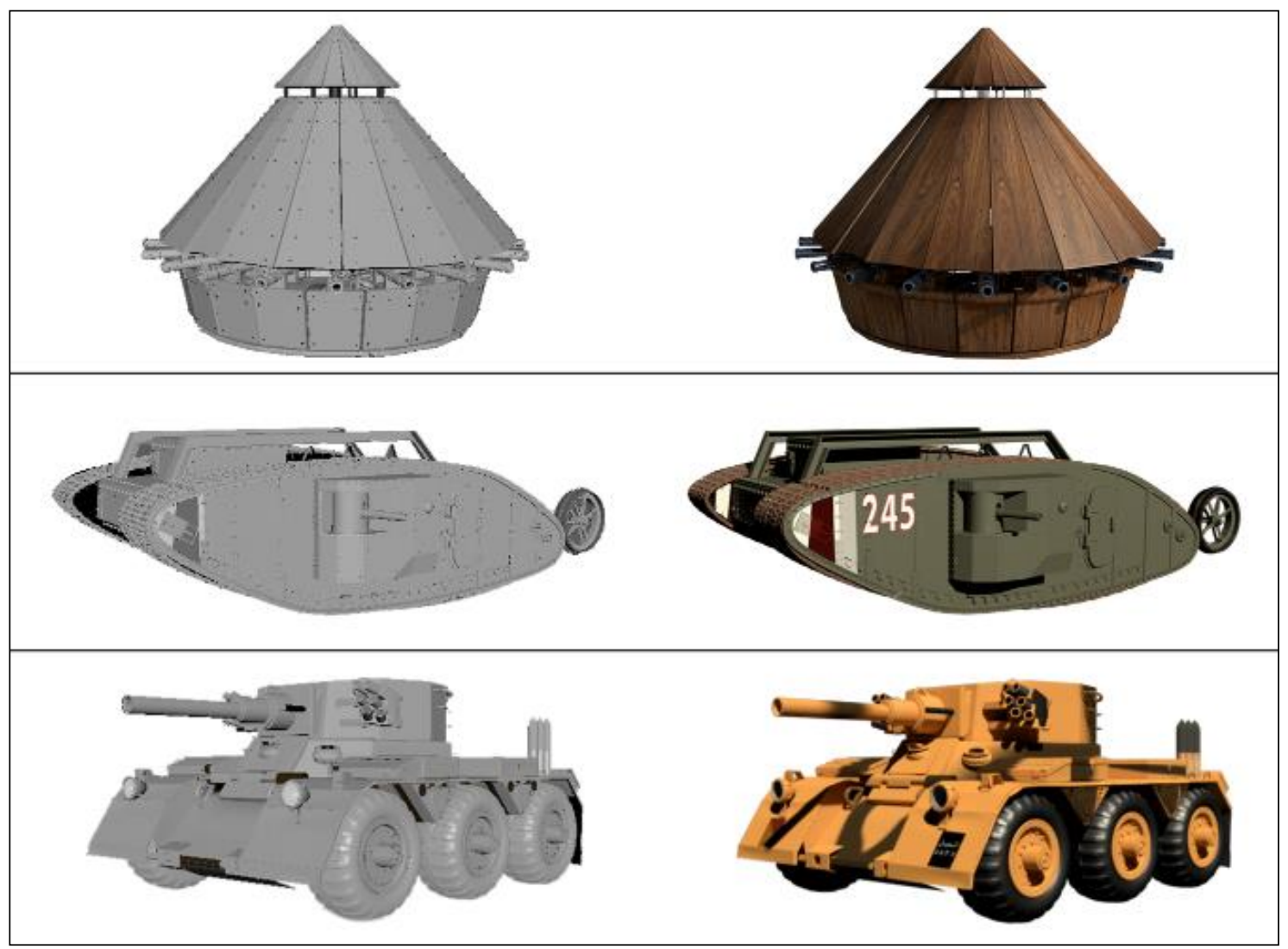

Figure 3. 3D modelling and texturing process 


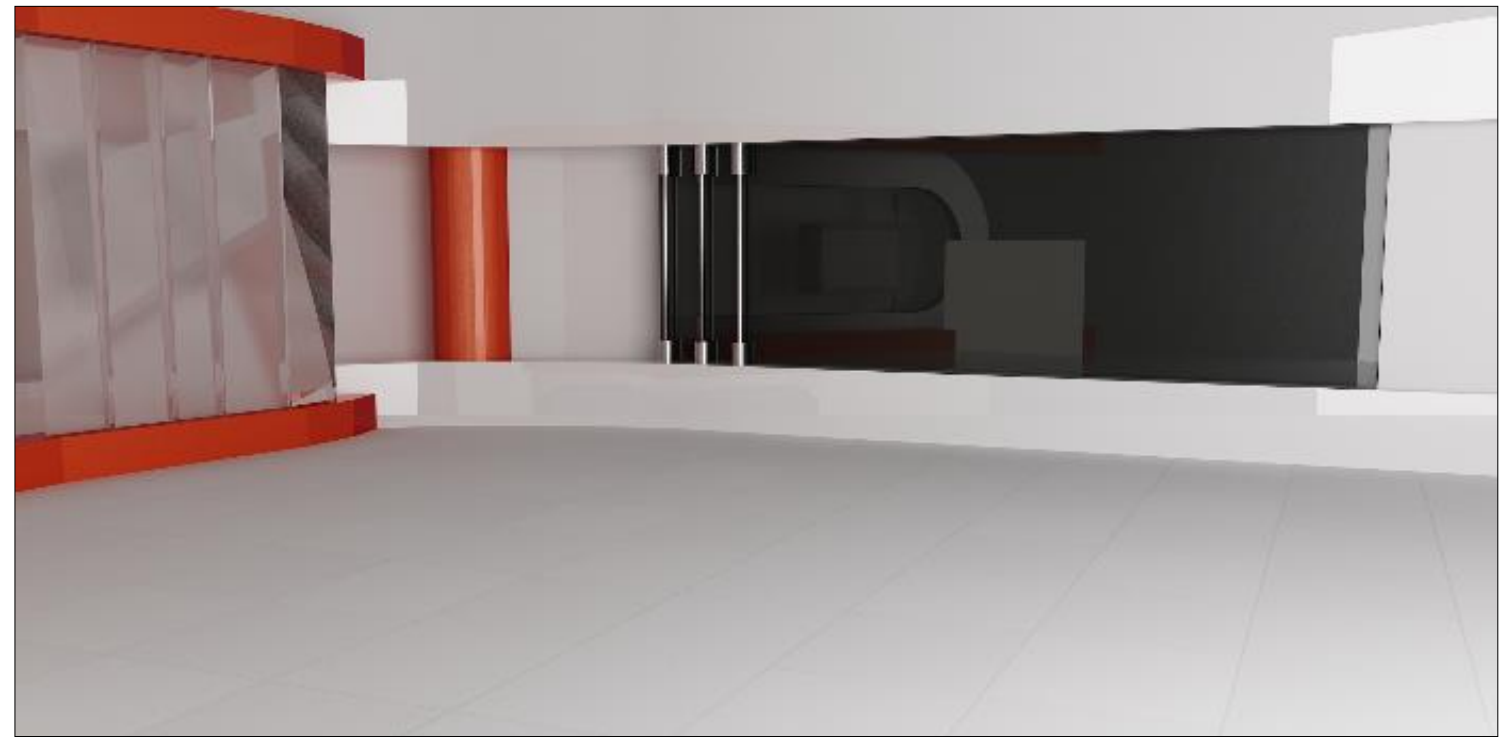

Figure 4. Virtual studio design

The storyboard phase (Figure 5) took place after the design of the VS and 3D modelling objects (tanks) was completed. The storyboard was created as an illustrative approach to guide the students in telling the story before the materials were recorded. It allowed them to understand their movement within the space of the VS and visualise the positions of the virtual animated objects. This was an important pre-directing stage that ensured a logical flow of the story, actions, camera shots, and angles [18].Furthermore, the TV directors could count on the previsualisation (Previs) before filming or recording using sketched storyboards, as mentioned previously, or taking advantage of digital technology to represent the visual style through rendering a 3D storyboard and using multimedia tools such as lights, visual effects, sound effects, and movement tracking of a camera in 3D space[19].
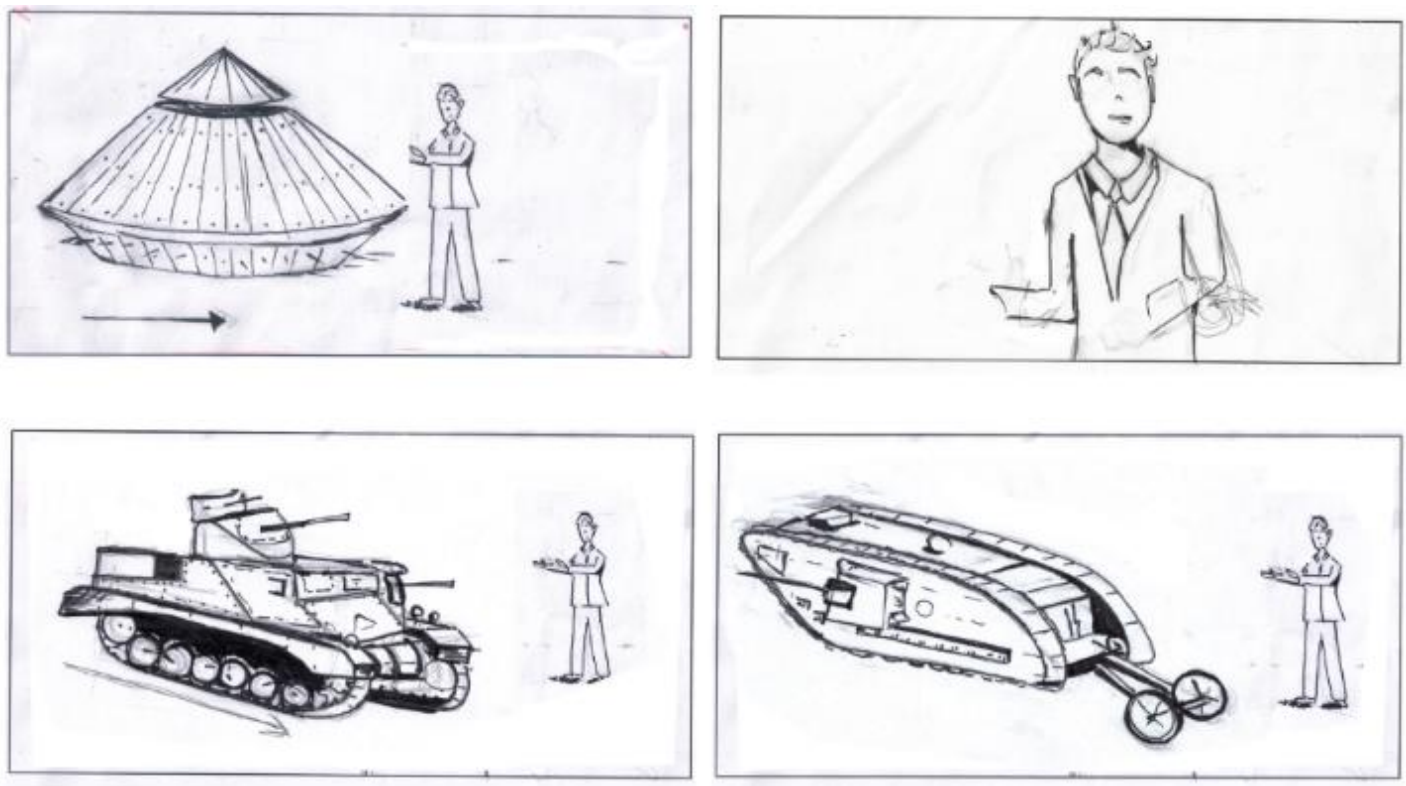

Figure 5. A storyboard of the 3D element movement within the studio space 
International Journal of Computer Graphics \& Animation (IJCGA) Vol.10, No.2/3, July 2020

The last phase for designing this experiment was the post-production process, which occurred after the material had been shot. All the graphics and videos were combined together before broadcasting, and virtual objects such as tanks 'fit into the recorded scene with the correct perspective, giving a natural impression of them belonging to the scenario.' [20]

\section{Evaluating Student Performance}

Three final-year media students were selected as participants in the experiment to evaluate their capability to interact with 3D AR in virtual broadcast news studios. None of the participants had previous experience in presenting news within a VS. The participants were University of Petra students in the Mass Communication Faculty's Radio and Television Programme. They were given a text on an event to be presented as a news story through the VS with virtual animated objects based on their skills gained during their studies at the university. The evaluation criteria focused on performance skills and interactivity between the participants and the 3D animated objects, and the evaluation was conducted in three phases, which are described in the following three subsections.

\subsection{Before the workshop}

The participants were unaware of the nature of the moving 3D virtual objects (tanks), which made their performance unpersuasive to the viewers. Their body language was unclear and did not correspond with what they said (Figure 6). Body language exposes what a person is thinking, and thus a presenter performing with virtual objects must provide a believable reaction to convince the viewer. Thus, this initial experiment clearly failed. The main problem was linking the participants and virtual 3D objects together and creating a relationship between them, especially since the students could not feel the presence of the $3 \mathrm{D}$ objects beside them due to the lack of visualisation, performance, and communication skills.

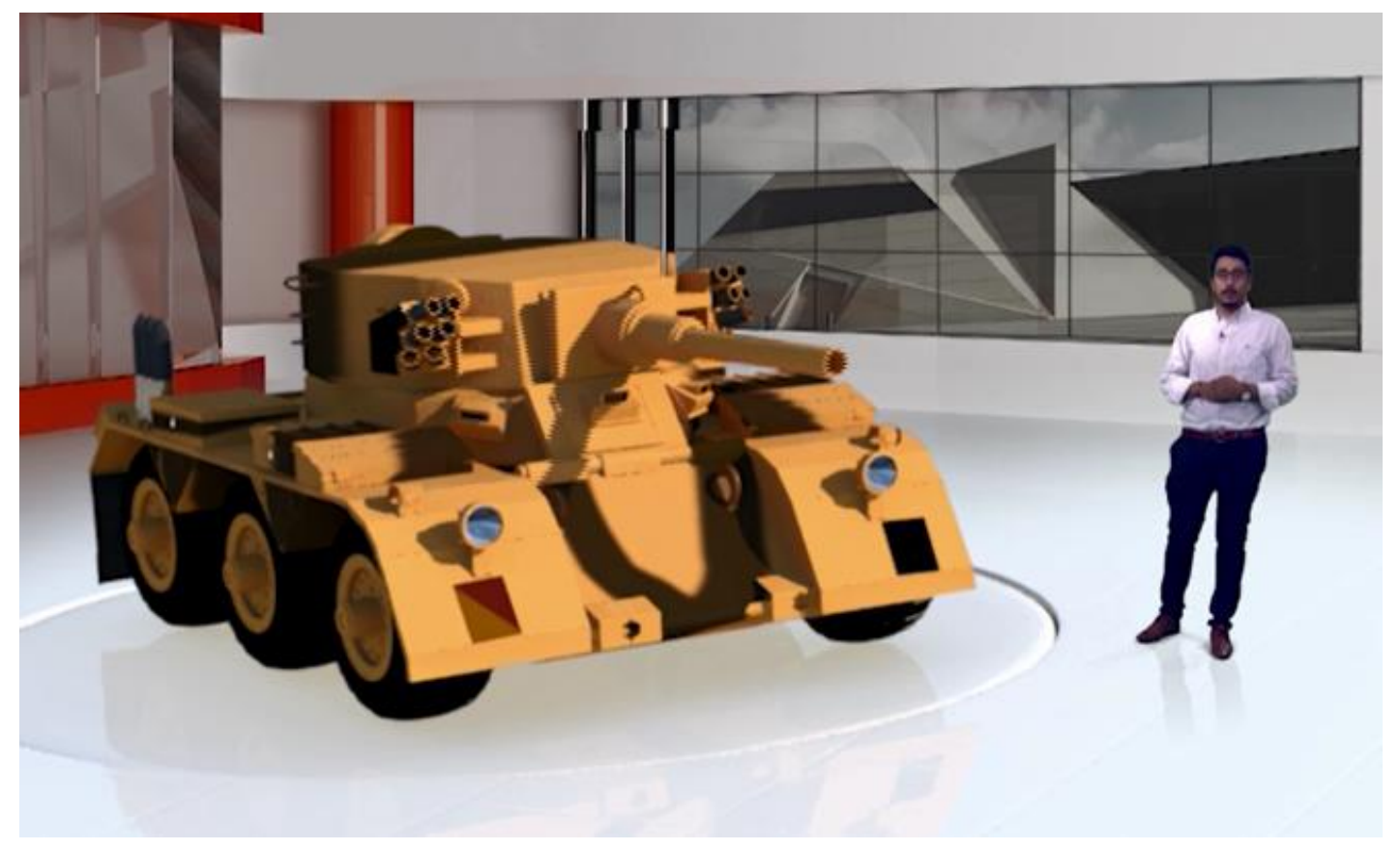

Figure 6. The lack of interaction between the participant and the virtual 3D object 


\subsection{The workshop}

We trained students through a workshop on communication skills and performance with animated virtual objects. A 10-hour workshop spanning 3 days was presented to the participants by Dr Hakim Masood. The workshop introduced students to the skills of mass communication, how to deal with body language, and how to present and picture the 3D objects within the VS to create a realistic and convincing sense of the presence of the presenter in the real environment.

\subsection{After the workshop}

The participants' performance had clearly improved; they controlled their facial expressions better and pronounced words correctly. They became more convincing in how they presented the news, used their body language, and interacted with the space and moving virtual objects, which made the viewers believe in the existence of these elements and the interaction between them (Figure 7). However, the workshop was short and not sufficient to help the students achieve a satisfactory performance; nonetheless, it provided an indication of the importance of performing skills for media students. The feedback from the participants about the whole experiment was positive; they indicated that such a new presentation method would enrich their practical experience, develop their persuasion skills, and improve the quality of viewers' news experience. Accordingly, we believe that this experiment was satisfying for both academics and students; however, the number of students was limited and the sample did not appear to provide significant results for this study. Thus, further research is required to engage more students in the future.

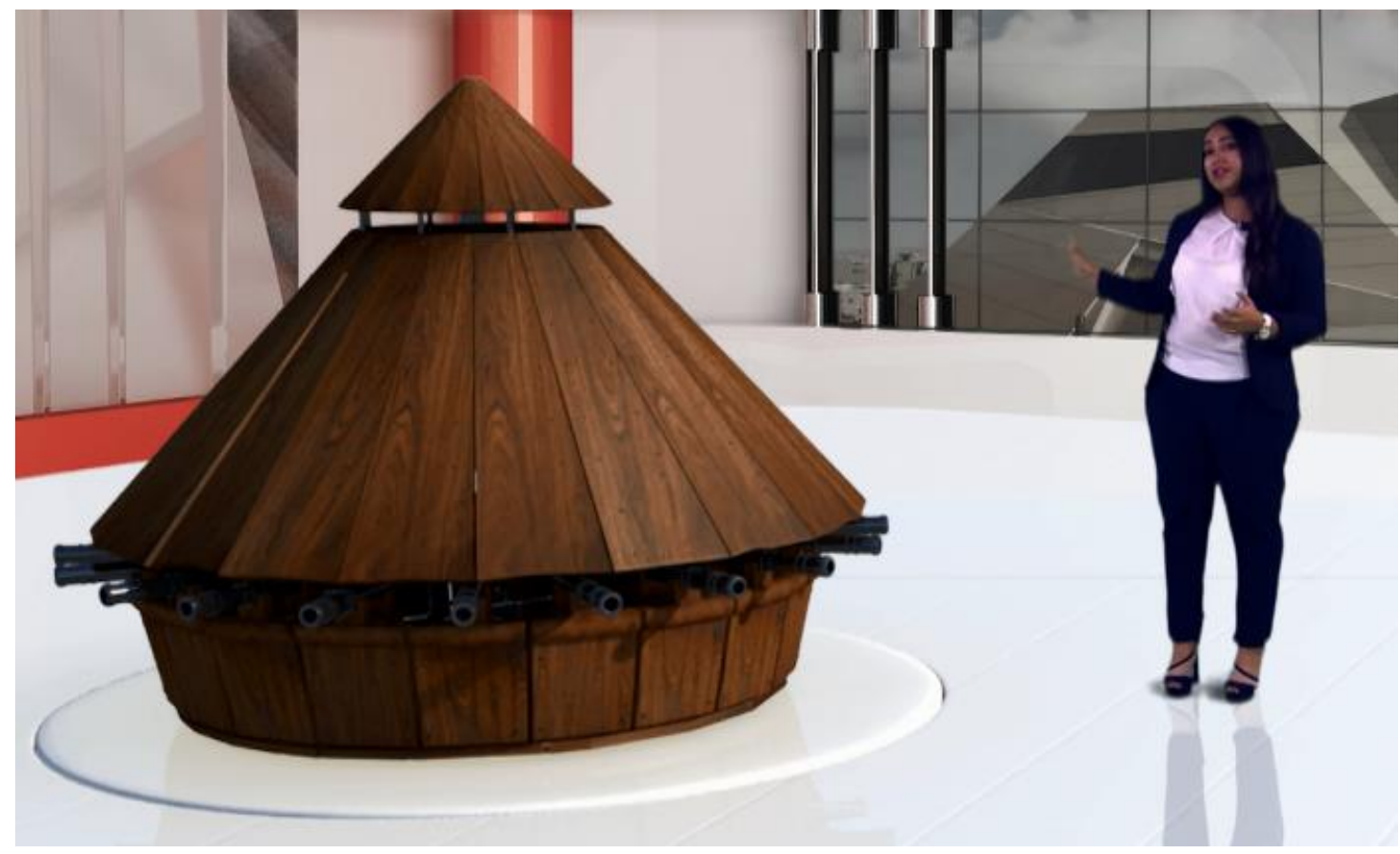

Figure 7. The participant interacts with the moving virtual objects

\section{Conclusion}

To answer the research questions from an educational point of view, we found that media students and graduates would be more successful in the media industry if they mastered the skills of communication, presentation, and acting performance to interact with virtual environments and virtual 3D animated objects. Furthermore, students should be a part of producing and designing 
International Journal of Computer Graphics \& Animation (IJCGA) Vol.10, No.2/3, July 2020

virtual elements such that they are more involved in the process; this approach will also encourage a positive relationship between them and virtual elements and will make the experience as realistic as possible for viewers. Therefore, the Department of Radio and Television should modify the curriculum by adding materials that specialise in acting performance when using a VS with all its tools for increasing students' experience in the evolving media field. Furthermore, instructors must improve their methods of teaching students to perform and present with AR.

One of this paper's main objectives is to present solutions and motivate universities in Jordan to apply the AR VS as a powerful tool for presenting stories. We believe the AR VS has the potential to be a crucial tool for television news broadcasting that could replace the traditional newsroom in the future. Future research should be chosen carefully to focus on the effectiveness of presentation using static graphics in the newsroom compared with animated graphics in the VS.

\section{ACKNOWLEDGEMENTS}

The authors gratefully acknowledge use of the services and facilities of the Studio1 and studio2 in the Faculty of Mass Communication. We also thank our colleagues from Animation \& Multimedia department, Raghad Awajneh and Yazan Nassrallah for creating all the 3D CG and animations. Also, from the Radio and Television department the technicians Doaa Sarayreh and Tayseer Jamzawi who provided insight and expertise that greatly assisted the practical work of this research. Moreover, the authors would like to thank the reviewers for their valuable comments.

\section{AVailability of Data AND Materials}

The datasets generated and analysed during the current study are available in the Google Drive repository, [https://drive.google.com/open?id=1 npv4a0OgwtdSaVc9ajdkIpaqOZoUHToH].

\section{ETHICS}

We confirm that the paper has not been published previously. The corresponding author confirms that all the other authors have read and approved the manuscript and no ethical issues involved.

\section{FUNDING}

This research was supported by the Deanship of Scientific Research, University of Petra $(1 / 5 / 2017)$.

\section{REFERENCES}

[1] MD. B. Islam and A.Ahmed and MD. K Islam and A. K Shamsuddin 'Child Education through Animation: An Experimental Study', International Journal of Computer Graphics \& Animation (IJCGA), Vol.4, No.4, October 2014, pp. 43-52

[2] N. Z. Amarin 'Beyond Segmented Instructional Animation and Its Role in Enrichment of Education and Technology', International Journal of Computer Graphics \& Animation (IJCGA), Vol.6, No.3, July 2016, pp. 17-33 
International Journal of Computer Graphics \& Animation (IJCGA) Vol.10, No.2/3, July 2020

[3] H. M. Omar, Y. K Hooi. and A. Sulaiman, "Design, implementation and evaluation of a Virtual Showroom," 2008 International Symposium on Information Technology, Kuala Lumpur, 2008, pp. 16.

[4] T.Keller, and S.Hawkins (2009), Television News, 3rdedn, Holcomb Hathaway Publishers, USA.

[5] S.Morey, and J.Tinnell(2017), Augmented Reality, Parlor Press, USA.

[6] P.Milgram, and F.Kishino 'A Taxonomy of Mixed Reality Visual Displays', IEICE Transactions on Information Systems, Vol.E77-D, No.12, Decempber 1994, pp. 1321-1329

[7] C.Fenu, and F.Pittarello 'Svevo tour: The design and the experimentation of an augmented reality application for engaging visitors of a literary museum', International Journal of Human-Computer Studies, vol. 114, June 2018, pp. 20-35.

[8] R.Azuma 'The Most Important Challenge Facing Augmented Reality', Presence, vol.25, No.3, Summer 2016, pp. 243-238

[9] N. Kim, W. Woo, G. J. Kim and C. -. Park, "3-D Virtual Studio for Natural Inter-“Acting”," in IEEE Transactions on Systems, Man, and Cybernetics - Part A: Systems and Humans, vol. 36, no. 4, pp. 758-773, July 2006, doi: 10.1109/TSMCA.2005.855752.

[10] Z. He and L. Wu and X. Li" When Art Meets Tech: The Role of Augmented Reality in Enhancing Museum Experiences and Purchase Intentions", Tourism Management, Volume 68, October 2018, pp 127-139

[11] R.K. Lowe, 2004, December. "Animation and learning: Value for money." In Beyond the comfort zone: Proceedings of the 21st ASCILITE Conference (Vol. 12, pp. 558-561).

[12] B. Tversky and J.B. Morrison, and \& M. Bétrancourt, “Animation: can it facilitate?", International Journal of Human-Computer Studies, Volume 57, Issue 4, October 2002, pp. 247-262

[13] R. Lloyd P., “Animation, Incidental Learning, and Continuing Motivation”, Journal of Educational Psychology Volume 83, Number 3, 1991, pp. 318-328

[14] R.K. Lowe, "Animation and learning: selective processing of information in dynamic graphics", Learning and Instruction, Volume 13, Issue 2, 2003, pp. 157-176

[15] T. Keller, and S. Hawkins (2009), Television News, 3rdedn, Holcomb Hathaway Publishers, USA.

[16] P. Dewan, "Words Versus Pictures: Leveraging the Research on Visual Communication", Partnership: The Canadian Journal of Library and Information Practice and Research, 10(1). Vol.10, no.1. June 2015

[17] A. Pennington (2015), Blending real and virtual elements on set: part1, viewed 30 October 2019, https://www.thebroadcastbridge.com/content/entry/1258/blending-real-and-virtual-elements-on-setpart-1

[18] G. Cristiano (2012), The Storyboard Design Course, 3rdedn, Thomas \& Hudson, London. Communication", Partnership: The Canadian Journal of Library and Information Practice and Research, 10(1). Vol.10, no.1. June 2015," 2008 International Symposium on Information Technology, Kuala Lumpur, 2008, pp. 1-6.

[19] C. Cram 'Digital Cinema: The Role of the Visual Effects Supervisor', Film History, Volume 24, pp. 169-186, 2012

[20] T. D. Kammann (2005), 'Interactive Augmented Reality in Digital Broadcasting Environments', Diploma thesis, University of Koblenz and Landau, Germany. 
International Journal of Computer Graphics \& Animation (IJCGA) Vol.10, No.2/3, July 2020

\section{AUTHORS BIOGRAPHY}

Tariq Alrimawi received his MA degree in Art of Animation from the University of South Wales, the UK in 2010, and the PhD degree in Animation from Loughborough University, the UK in 2014. He wrote and directed three short-animated films 'Missing' in 2010, 'Growing' in 2013, and 'Surprise' in 2016. His shorts have been screened at more than 180 international film festivals and received 15 awards domestically and internationally. In 2016, he established the Animation \& Multimedia Department at the University of Petra and currently working as an assistant professor

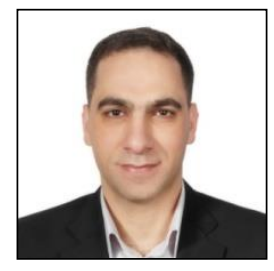
at the Faculty of Architecture and Design at the University of Petra. His research interests are the Arab Animation Industry and Animation in Education.

Wasan Haddad is a documentary filmmaker and a lecturer in the department of Radio and elevision at the faculty of Mass Communication at the University of Petra. She received her MA Degree in Documentary Practice from Brunel West- London in 2010, the UK. Haddad is a member of quality assurance at faculty, and the committee to write a module under a title of "Cinema in Education" - a project for Karama Fesitval in cooperation with UNISCO-, and she was a member of committee to write a curriculum under the title " how to use the journalistic skills to highlight environmental issue at Jordan" with JREDS the Royal marine conservation society

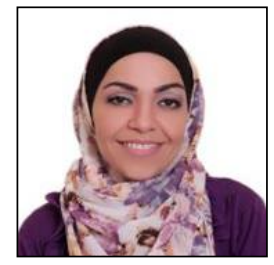
of Jordan. 